\section{Provokationsfaktor Malassezia}

\author{
Es gilt heute als sicher, dass der opportunistische Hefepilz \\ Malassezia ein Triggerfaktor der atopischen Dermatitis ist. In einer \\ Übersichtsarbeit versuchten schwedische Allergologen seiner Rolle \\ genauer auf die Spur zu kommen.
}

$E_{\text {hi }}^{\text {in }}$ ine Beteiligung von Malassezia (früher Pityrosporum) an der Pathophysiologie der atpoischen Dermatitis wird seit nahezu 20 Jahren diskutiert. In einigen Studien gelang eine Verbesserung des Hautzustands Betroffener durch eine Ketoconazol-Therapie.

Bisher war bekannt, dass sich die Hefe vor allem bei Lokalisation der Hautveränderungen im Kopf-HalsNacken-Bereich findet. Im AtopiePatchtest reagierten aber auch Patienten ohne Kopf-Hals-Dermatitis sowie solche mit niedrigem Gesamt-IgE.
Interessanterweise ist der AtopiePatchtest gegen Malassezia manchmal positiv, obwohl kein spezifisches Serum-IgE detektierbar oder der Pricktest negativ ist. Ein solches Reaktionsmuster wird bei Atopikern auch manchmal für bestimmte Aeroallergene gefunden. Bestandteile von Malassezia könnten als diagnostisches Tool vielleicht dabei helfen, verschiedene Patienten-Subgruppen zu identifizieren.

Fazit: An die Möglichkeit einer Überempfindlichkeit gegenüber Malassezia

\section{Malassezia: Who is who?}

Die Hefepilzgattung Malassezia kolonisiert das Stratum corneum und die Haarfollikel und ist vor allem an talgdrüsenreichen Hautstellen vertreten. Die meisten Arten benötigen für ihr Wachstum langkettige Fettsäuren. Meist harmlos, vermag der Pilz aber auch Hautund sogar systemische Infektionen auszulösen. Er ist verursachendes Agens für Pityriasis versicolor und PityrosporumFollikulitis und spielt eine Rolle in der Pathogenese des seborrhoischen wie des atopischen Ekzems.

sollte auch bei Patienten ohne KopfHals-Dermatitis und auch bei unauffälligem Gesamt-IgE gedacht werden. Durch einen Atopie-Patchtest könnten diese Fälle aufgespürt werden. $\quad w p a$

Scheynius A et al. Atopic eczema/dermatitis syndrome and malassezia. Int Arch Allergy Immunol 2002; 127: 161-9

\title{
Haustiere: Auf die Dosis kommt es an
}

\section{Die Frage, ob Haustiere die Entstehung von Allergien bei Kindern fördern, lässt sich je nach betrachteter Studie mal mit Ja, mal mit Nein beantworten. In diese Diskussion bringen Allergologen von der Universität Detroit jetzt einen interessanten neuen Aspekt ein.}

\begin{abstract}
$\mathrm{n}$ eine Kohortenstudie wurde der Lebenslauf von Kindern dokumentiert, die im ersten Lebensjahr ohne, mit einem oder mit mindestens zwei Haustieren aufwuchsen. Im Alter zwischen 6 und 7 Jahren führten die Ärzte bei 474 dieser Kinder einen Allergietest durch.
\end{abstract}

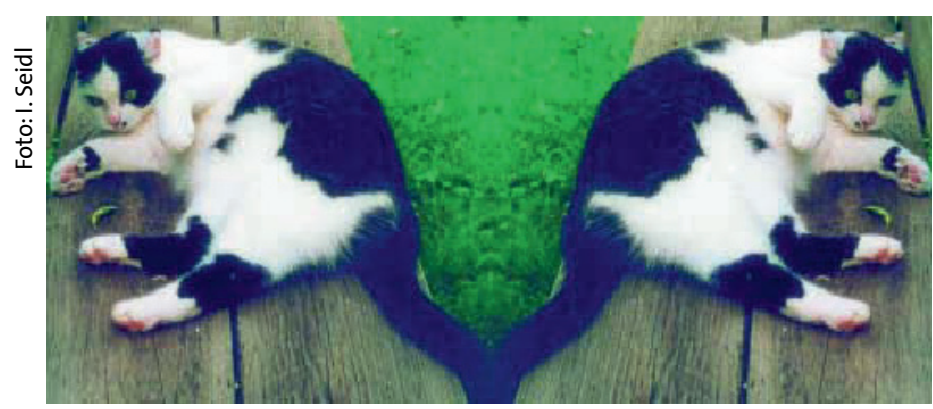

Nimm zwei! Ein Haustier erhöht das Atopierisko, zwei oder mehr dagegen reduzieren es - sagt die Statistik.
„Atopie“ wurde diagnostiziert, wenn der Pricktest gegen mindestens eines von sechs Inhalationsallergenen (Hundeund Katzenhaar, zwei Hausstaubmilbenspezies, Traubenkraut, Wiesenrispe) positiv ausfiel. Von „serologischer Atopie" war die Rede, wenn mindestens ein spezifischer IgE-Test gegen die genannten Allergene oder gegen Alternariaspezies positiv ausfiel.

Waren die Kinder im ersten Lebensjahr ohne Haustiere aufgewachsen, zeigte sich ein positiver Pricktest bei $33,6 \%$. Hatte es in diesem Zeitraum engen Kontakt mit ei- nem Hund oder einer Katze gegeben, fiel der Pricktest unmerklich häufiger, nämlich in 34,3\% der Fälle, positiv aus. Bei Kindern, die mit mindestens zwei Haustieren zusammengelebt hatten, reduzierte sich dagegen der Prozentsatz positiver Reaktionen auf weniger als die Hälfte (15,4\%). Dieser Unterschied war hoch signifikant. Bei den „serologischen Atopien“ zeigten sich ähnliche Werte: Der Anteil von Kindern mit positivem spezifischem IgE-Nachweis lag ohne Haustierkontakt bei $38,5 \%$, bei Kontakt mit nur einem Haustier bei $41,2 \%$ und - wieder mit hoch signifikantem Unterschied - bei regelmäßigem Kontakt mit zwei oder mehr Haustieren bei $17,9 \%$

Fazit: Kinder mit engem Kontakt zu zwei oder mehr Haustieren innerhalb des ersten Lebensjahres haben ein signifikant geringeres Sensibilisierungsrisiko. Wieso der Kontakt mit nur einem Haustier keine messbare Assoziation mit dem Atopierisiko hat, bleibt unklar. af

Ownby DR et al. Exposure to dogs and cats in the first year of life and risk of allergic sensitization at 6 to 7 years of age. JAMA 2002; 288: 963-72 